\title{
Hubungan Aspek Area Klinis Dan Area Manajerial Terhadap Keselamatan Pasien
}

\section{The Relationship of Clinical Areas and Managerial Areas To The Safety of Patients}

\author{
M. Iskandar*, Wahyu Sulistiadi*, Syafiul A. Sjaaf* \\ *Universitas Respati Indonesia \\ Email : iskandargreat013@gmail.com, \\ RS. Dr. Suyoto Jl. RC Veteran No. 178 Jakarta Selatan
}

\begin{abstract}
ABSTRAK
Rumah Sakit dr. Suyoto telah mendapatkan akreditasi paripurna dari Komite Akreditasi Rumah Sakit (KARS) Versi 2012. Akan tetapi dalam perjalanannya, program mutu dan keselamatan pasien kurang berkembang yang ditandai dengan penurunan nilai indikator mutu klinik dan mutu manajerial serta terjadinya insiden Kejadian Nyaris Cidera (KNC) dan Kejadian Tidak Diharapkan (KTD), seperti pemberian obat jadi yang nyaris salah pasien serta pasien jatuh dari tempat tidur di ruang rawat inap. Atas kejadian ini maka pencapaian nilai indikator mutu klinik dan nilai indikator mutu manajerial serta mencari hubungan atau korelasi indikator mutu klinik dan manajerial dengan Sasaran Keselamatan Pasien (SKP) ini dilakukan. Penelitian ini merupakan penelitian kuantitatif non eksperimental dengan pendekatan cross sectional dengan sampling populasi pasien rawat inap, petugas kesehatan, sampling pasien radiologi, dan sampling pasien laboratorium. Hasil penelitian didapatkan nilai mutu klinik dan manajerial yang sudah mendekati nilai $80 \%$, didapatkan sebagian indikator mutu klinik dan manajerial mempunyai hubungan atau korelasi dengan sasaran keselamatan pasien. Simpulan dari penelitian ini adala nilai indikator mutu klinik dan manajerial sudah mendekati standar mutu KARS 2012 namun perlu ditingkatkan lagi.
\end{abstract}

\section{Kata Kunci : Indikator Mutu Klinik, Manajerial, Sasaran Keselamatan Pasien}

\section{ABSTRACT}

Hospital Dr. Suyoto has received plenary accreditation from the 2012 Hospital Accreditation Committee (KARS) Version. However, in the course of the program, the patient's quality and safety program was underdeveloped which was marked by a decrease in the value of clinical quality indicators and managerial quality as well as the incidence of Near Injury (KNC) and Events. Not Expected (KTD), such as giving drugs that are almost wrong patients and patients fall from bed in the inpatient room. For this incident, research on how far the achievement of clinical quality indicators and managerial quality indicators and the relationship or correlation between clinical and managerial quality indicators and Patient Safety Goals (SKP) is carried out. This study is a quantitative non-experimental study with a cross sectional approach with sampling inpatient population, health workers, radiology patient sampling, and laboratory patient sampling. Results of the study obtained clinical and managerial quality values that have approached $80 \%$, found that some clinical and managerial quality indicators have a relationship or correlation with patient safety goals.

Keywords: Clinical Quality, Managerial Indicators, Patient Safety Goals 


\section{PENDAHULUAN}

Pengertian mutu pelayanan rumah sakit yaitu tingkat derajat kesempurnaan suatu pelayanan oleh rumah sakit yang bertujuan untuk memenuhi harapan atau kebutuhan pasien dan keluarga akan pelayanan kesehatan yang sesuai dengan standar yang telah ditetapkan oleh pemerintah. Standar adalah nilai tertentu yang telah ditetapkan berkaitan dengan indikator sesuatu yang harus dicapai.

Standar mutu pelayanan unit kerja rumah sakit dapat diukur dengan menggunakan indikator standar yang dipakai pada akreditasi rumah sakit yang ditentukan oleh Komite Akreditasi Rumah Sakit (KARS) versi 2012 yaitu 11 indikator area klinik dan 9 indikator area manajerial. Pengukuran menggunakan standar KARS versi 2012 saat ini cukup penting dan beralasan kuat karena standar ini selalu dipakai oleh Surveyor dalam menilai peringkat akreditasi rumah sakit setiap 3 tahun sekali.

Akreditasi rumah sakit adalah pengakuan terhadap rumah sakit yang diberikan oleh lembaga independen penyelenggara akreditasi yang ditetapkan oleh menteri kesehatan. Rumah sakit wajib melakukan akreditasi dalam upayanya meningkatkan mutu pelayanan secara berkala setiap 3 (tiga) tahun sekali sebagaimana tercantum dalam Undang-Undang Nomor 44 Tahun 2009 tentang Rumah Sakit.

Keselamatan pasien merupakan langkah kritis pertama untuk memperbaiki kualitas pelayanan. Tercermin pada laporan (Institute OF Medicine/IOM 2000) di Amerika Serikat daerah Utah dan Colorado ditemukan kejadian tidak diinginkan sebesar 2,9\% dimana 6,6 \% meninggal dunia, sedangkan di New York sebesar 3,7\% angka kejadian tidak diinginkan dengan angka kematian 13,6\%. Angka kematian akibat KTD di bagian rawat inap di seluruh Amerika berkisar 44.00098.000 pertahunnya. Pada Kongres Nasional Perhimpunan Rumah Sakit Seluruh Indonesia(PERSI) XXI di Jakarta pada tanggal 8 November 2012 melaporkan angka kejadian pasien jatuh pada bulan Januari sampai September 2012 sebesar $14 \%$.

Hal ini membuat presentasi angka kejadian pasien jatuh termasuk dalam lima besar insiden medis. Tim Keselamatan Pasien Rumah Sakit (TKPRS) yang di 
bentuk di Rumah Sakit Dr. Suyoto berdasarkan Surat Keputusan Karumkit telah menerapkan dan membentuk kebijakan tentang pencegah risiko keselamatan pasien. Rumah Sakit Dr. Suyoto sudah terakreditasi oleh KARS (Komite Akreditasi Rumah Sakit) versi 2012, selain itu Rumah Sakit Dr. Suyoto merupakan salah satu rumah sakit pemerintah yang menjadi salah satu rumah sakit rujukan di kota Jakarta Selatan.

Rumah Sakit Dr. Suyoto berkomitmen pada keselamatan pasien dengan telah memiliki SPO (Standar Prosedur Operasional). Pelaporan terhadap kejadian insiden keselamatan pasien di Rumah Sakit Dr. Suyoto untuk yang bersifat sentinel tidak ditemukan, tetapi ada laporan KTD (Kejadian Tidak Diharapkan) pasien jatuh, atau KNC pasien nyaris jatuh termasuk KNC berupa kesalahan penulisan resep obat. Tidak menutup kemungkinan dengan angka kunjungan yang tinggi dan status rumah sakit rujukan akan meningkatkan risiko kejadian patient safety. Adanya laporan kejadian tidak diharapkan dan kejadian nyaris cedera sudah ditindaklanjuti dan sudah ada rekomendasinya.

Rumah Sakit Dr. Suyoto merupakan rumah sakit yang dimiliki oleh Kementerian Pertahanan RI yang terletak di Jl RC Veteran Bintaro Jakarta Selatan dan sudah terakreditasi paripurna tahun 2016. Rumah Sakit Dr. Suyoto berfungsi memberikan pelayanan perumahsakitan untuk Kedinasan TNI/PNS Kemhan dan juga masyarakat umum baik BPJS/Asuransi dan Swasta. Dengan berubahnya pembiayaan kesehatan ke era Jaminan Kesehatan Nasional (JKN) yang dimulai tahun 2014, maka membawa perubahan komposisi pasien yang berobat ke Rumah Sakit Dr. Suyoto menjadi 90\% pasien tanggungan BPJS (Badan Penyelenggara Jaminan Sosial), 5\% asuransi dan 5\% swasta. Perubahan komposisi pasien ini dikhawatirkan dapat merubah mutu pelayanan kesehatan dan berdampak pada keselamatan pasien yang berobat di Rumah Sakit Dr. Suyoto Jakarta sehingga perlu dilakukan pengukuran melalui indikator-indikator yang telah ditetapkan oleh KARS 2012. 


\section{METODE}

Desain yang digunakan dalam penelitian ini adalah crossectional dengan pendekatan kuantitatif. Pengambilan sampel pada penelitian ini menggunakan probability sampling dengan teknik proporsionate random sampling dan rumus slovin untuk menentukan jumlah sampel karena populasi relatif homogen sehingga tidak terlalu diperlukan untuk distratifikasi dan terdapat jumlah populasi yang jelas. Rumus slovin sebagai berikut:

$$
\mathrm{n}=\frac{\mathrm{N}}{1+\mathrm{N}(\mathrm{e})^{2}}
$$

Keterangan:

$\mathrm{n}=$ jumlah sampel

$\mathrm{N}=$ jumlah populasi

e = error levei (tingkat kesalahan) 1\%, 5\%, 10\%

Jumlah pasien rawat inap rata-rata 200 pasien/bulan

\section{HASIL}

Analisis univariat dalam penelitian ini digunakan untuk menguji IMK (Indikator Mutu Klinik) dan IMM (Indikator Mutu Manajerial), dengan hasil sebagai berikut. Hasil analisis kelengkapan pengkajian awal medis disajikan dalam Tabel 1 sebagai berikut.

\section{Tabel 1. IMK Kelengkapan Pengkajian Awal Medis}

\begin{tabular}{lccc}
\hline Kelengkapan pengkajian & Frekuensi & Pencapaian \% & Standar \\
\hline Lengkap & 33 & 55,0 & \\
Tidak Lengkap & 27 & 45,0 & $100 \%$ \\
Total & 60 & 100,0 & \\
\hline
\end{tabular}

Tabel 4 diperoleh informasi hasil status rekam medis dengan pengkajian awal medis lengkap 55\% dan tidak lengkap 45\%. Belum memenuhi standar yang diterapkan yaitu 100\%. IMK Waktu Tunggu Pemeriksaan Laboratorium sebagai berikut :

Tabel 2. IMK Waktu Tunggu Pemeriksaan Laboratorium

\begin{tabular}{lccl}
\hline Waktu tunggu & Frequensi & Pencapaian\% & Standar \\
\hline Terpenuhi & 42 & 70,0 & $100 \%$ (Kurang dari \\
Tidak Terpenuhi & 18 & 30,0 & 120 menit) \\
Total & 60 & 100,0 & \\
\hline
\end{tabular}

Tabel 5 diperoleh informasi hasil waktu tunggu pemeriksaan laboratorium terpenuhi (kurang dari 120 menit) adalah 70\% dan tidak terpenuhi (lebih dari 120 
menit) 30\%. Hasil analisis penulisan resep obat yang sesuai dengan formularium nasional disajikan dalam Tabel 3 sebagai berikut :

Tabel 3. IMK Penulisan Resep Obat Sesuai Formularium Nasional

\begin{tabular}{lccc}
\hline Formularium Nasional & Frekuensi & Pencapaian\% & Standar \\
\hline Sesuai & 46 & 76,7 & \\
Tidak Sesuai & 14 & 23,3 & $100 \%$ \\
Total & 60 & 100,0 & \\
\hline
\end{tabular}

Tabel 3 didapatkan hasil penulisan resep obat sesuai formularium nasional $76,7 \%$ dan tidak sesuai dengan formularium nasional 23,3\%, sedangkan standarnya adalah 100\%. Hasil analisis kesalahan peresepan obat disajikan dalam Tabel 4 sebagai berikut :

Tabel 4. IMK Kesalahan Peresepan Obat

\begin{tabular}{lccc}
\hline Kesalahan Resep & Frekuensi & Persentase pencapaian & Standar \\
\hline Tidak Ada kesalahan & 48 & 80,0 & \\
Ada kesalahan & 12 & 20,0 & $100 \%$ \\
Total & 60 & 100,0 & \\
\hline
\end{tabular}

Tabel 3 didapatkan hasil tidak ada kesalahan Penulisan Resep Obat adalah $80 \%$ dan ada kesalahan penulisan resep obat 20\%, sedangkan standarnya $100 \%$ tidak ada kesalahan. Hasil analisis kelengkapan rekam medik dalam waktu 1x24 jam disajikan dalam Tabel 8 sebagai berikut.

\section{Tabel 5. IMK Kelengkapan Rekam Medik dalam Waktu 1x24 Jam}

\begin{tabular}{lccc}
\hline Kelengkapan Rekam Medik & Frekuensi & $\begin{array}{c}\text { Persentase } \\
\text { Pencapaian }\end{array}$ & Standar \\
\hline Lengkap & 31 & 51,7 & \\
Tidak Lengkap & 29 & 48,3 & $100 \%$ \\
Total & 60 & 100,0 & \\
\hline
\end{tabular}

Tabel 5 didapatkan hasil status rekam medik lengkap 51,7\% sedangkan status rekam medik tidak lengkap 48,3\%. Standar baku adalah 100\%. Hasil analisis pelaksanaan time out di kamar operasi disajikan dalam Tabel 9 sebagai berikut.

\section{Tabel 6. IMK Pelaksanaan Time Out di Kamar Operasi}

\begin{tabular}{lccc}
\hline Pelaksanaan Time Out & Frekuensi & Persentase & Standar \\
\hline Dilaksanakan & 40 & 66,7 & \\
Tidak Dilaksanakan & 20 & 33,3 & $100 \%$ \\
Total & 60 & 100,0 & \\
\hline
\end{tabular}


Tabel 6 didapatkan hasil pelaksanaan time out di kamar operasi 66,7\% dan tidak dilaksanakan sebanyak 33,3\%. Standar pelaksanaan 100\%. Hasil analisis kelengkapan pengkajian pra-anastesi sebelum tindakan operasi disajikan dalam Tabel 7 berikut ini :

\begin{tabular}{|c|c|c|c|}
\hline Pengkajian Pra Anastesi & Frequensi & $\begin{array}{l}\text { Persentase } \\
\text { pencapaian }\end{array}$ & Standar \\
\hline Dikaji & 39 & 65,0 & \\
\hline Tidak Dikaji & 21 & 35,0 & $100 \%$ \\
\hline Total & 60 & 100,0 & \\
\hline
\end{tabular}

Tabel 7 didapatkan hasil dilakukan pengkajian pra-anastesi sebelum tindakan operasi $65 \%$ dan tidak dikaji sebesar 35\%. Standar 100\% dilakukan pengkajian. Infeksi Daerah Operasi yaitu Infeksi yang terjadi pada daerah insisi daerah operasi dalam waktu 30 hari tanpa implan dan satu tahun dengan implan pasca bedah. Hasil analisis terjadinya infeksi daerah operasi disajikan dalam Tabel 8 berikut.

\section{Tabel 8. IMK Terjadinya Infeksi Daerah Operasi}

\begin{tabular}{lccc}
\hline Infeksi Daerah Operasi & Frequensi & Persentase & Standar \\
\hline Tidak ada Infeksi & 58 & 96,7 & \\
Ada Infeksi & 2 & 3,3 & $100 \%$ \\
Total & 60 & 100,0 & \\
\hline
\end{tabular}

Tabel 8 didapatkan hasil tidak Terjadi Infeksi Daerah Operasi sebesar 96,7\% sedangkan Terjadi Infeksi Daerah Operasi sebesar 3,3\%. Standar 100\% tidak ada IDO. Reaksi transfusi merupakan kejadian tidak diharapkan (KTD) yang terjadi akibat transfusi darah dalam bentuk reaksi alergi, infeksi akibat transfusi, hemolisis akibat golongan darah tidak sesuai,gangguan sistem imun sebagai akibat pembeban transfusi darah, reaksi ini dinyatakan terjadi pada saat 1 jam pertama sejak pemberian darah. Hasil analisis terjadinya reaksi tranfusi pada pasien disajikan dalam Tabel 12 berikut.

Tabel 9. IMK Terjadinya Reaksi Tranfusi pada pasien

\begin{tabular}{lccc}
\hline Reaksi Tranfusi & Frequensi & Persentase & Standar \\
\hline Tidak Mengalami & 57 & 95,0 & \\
Mengalami & 3 & 5,0 & $100 \%$ \\
Total & 60 & 100,0 & \\
\hline
\end{tabular}


M. Iskandar, Wahyu Sulistiadi, Syafiul A. Sjaaf : Hubungan Aspek Area Klinis Dan A...

Tabel 9 didapatkan hasil tidak terjadi reaksi tranfusi sebesar 95\% sedangkan terjadi reaksi tranfusi sebesar 5\%. Standar 100\% tidak terjadi reaksi tranfusi. Hasil analisis pelaksanaan expertisi oleh radiolog disajikan dalam Tabel 10 sebagai berikut :

Tabel 10. IMK Pelaksanaan Expertisi Oleh Radiolog

\begin{tabular}{lccc}
\hline Pelaksanaan expertisi & Frequensi & Persentase & Standar \\
\hline Ekpertisi & 39 & 65,0 & \\
Tidak Diekspertisi & 21 & 35,0 & $100 \%$ \\
Total & 60 & 100,0 & \\
\hline
\end{tabular}

Tabel 10 didapatkan hasil 65\% diexpertisi, 35\% tidak diexpertisi, sedangkan standarnya adalah $100 \%$. Hasil analisis jumlah pasien jatuh saat rawat inap disajikan dalam Tabel 11 berikut.

Tabel 11. IMM Jumlah Pasien Jatuh Saat Rawat Inap

\begin{tabular}{lccc}
\hline Jumlah Pasien Jatuh & Frequensi & Persentase & Standar \\
\hline Tidak Jatuh & 58 & 96,7 & \\
Jatuh & 2 & 3,3 & $100 \%$ \\
Total & 60 & 100,0 & \\
\hline
\end{tabular}

Tabel 11 didapatkan hasil pasien tidak jatuh di ruang rawat inap sebesar 96,7\% sedangkan pasien jatuh dirawat inap sebesar 3,3\%.

Kepuasan kerja karyawan adalah terpenuhi atau tidaknya keinginan mereka terhadap pekerjaan. Apabila dalam lingkungan kerja seorang karyawan tidak mendapatkan apa yang diharapkan diantarannya peluang promosi yang adil, pendapatan yang baik, rekan kerja dan atasan yang menyenangkan, serta kepuasan terhadap pekerjaan itu sendiri maka dapat dipastikan kinerja karyawan akan buruk. Hasil analisis kepuasan pegawai terhadap kondisi lingkungan kerja disajikan dalam Tabel 12 berikut.

\section{Tabel 12. IMM Kepuasan Pegawai Terhadap Kondisi Lingkungan Kerja}

\begin{tabular}{lccc}
\hline Kepuasan Pegawai & Frekuensi & Persentase & Standar \\
\hline Puas & 43 & 71,7 & \\
Tidak Puas & 17 & 28,3 & $80 \%$ \\
Total & 60 & 100,0 & \\
\hline
\end{tabular}

Tabel 12 didapatkan hasil pegawai yang puas terhadap kondisi lingkungan kerja sebesar 71,7\%, sedangkan pegawai yang tidak puas terhadap kondisi lingkungan kerja sebesar 28,3\%. Standar kepuasan pegawai adalah 80\%. 
Kepatuhan cuci tangan adalah ketaatan petugas dalam melakukan prosedur cuci tangan dengan menggunakan metode 6 langkah dan lima momen. Hasil analisis petugas kesehatan melakukan kebersihan tangan dengan metode enam langkah dan lima momen disajikan dalam Tabel 13 berikut.

\section{Tabel 13. IMM Petugas Kesehatan Melakukan Kebersihan Tangan dengan Metode Enam Langkah dan Lima Momen}

\begin{tabular}{lccc}
\hline Kebersihan Tangan & Frekuensi & Persentase & Standar \\
\hline Melaksanakan & 49 & 81,7 & \\
Tidak Melaksanakan & 11 & 18,3 & $100 \%$ \\
Total & 60 & 100,0 & \\
\hline
\end{tabular}

Tabel 13 didapatkan hasil petugas kesehatan melakukan kebersihan tangan dengan metode enam langkah dan lima momen sebesar 81,7\% sedangkan yang tidak melakukan sebesar 18,3\%. Standar melaksanakan kebersihan tangan 100\%. Pemanfaatan alat $M R I$ adalah angka yang menunjukkan jumlah pemakaian alat $M R I$ sesuai dengan indikasi dan urgensi keperluan penggunaanya. Alat MRI yang digunakan memang benar-benar sesuai dengan indikasi pemeriksaan yang dibutuhkan untuk mempercepat proses diagnosis. Dalam pengukuran indkator ini akan difokuskan untuk MRI dalam proses diagnostik yang dilaksanakan. Hasil analisis penggunaan alat medis canggih MRI sesuai indikasi disajikan dalam Tabel 13 berikut.

Tabel 14. IMM Penggunaan Alat Medis Canggih MRI Sesuai Indikasi

\begin{tabular}{lccc}
\hline Penggunaan MRI & Frekuensi & Persentase & Standar \\
\hline Sesuai Indikasi & 46 & 76,7 & \\
Tidak Sesuai Indikasi & 14 & 23,3 & $100 \%$ \\
Total & 60 & 100,0 & \\
\hline
\end{tabular}

Tabel 14 didapatkan hasil penggunaan alat medis canggih MRI sesuai indikasi sebesar 76,7\%.sedangkan penggunaan alat medis canggih MRI tidak sesuai indikasi sebesar 23,3\%. Hasil analisis kepuasan pasien di ruang rawat inap disajikan dalam Tabel 15 sebagai berikut.

Tabel 15. IMM Kepuasan Pasien di Ruang Rawat Inap

\begin{tabular}{lccc}
\hline Kepuasan Pasien & Frekuensi & Persentase & Standar \\
\hline Puas & 46 & 76,7 & \\
Tidak Puas & 14 & 23,3 & $80 \%$ \\
Total & 60 & 100,0 & \\
\hline
\end{tabular}


M. Iskandar, Wahyu Sulistiadi, Syafiul A. Sjaaf : Hubungan Aspek Area Klinis Dan A...

Tabel 15 didapatkan hasil kepuasan pasien di ruang rawat inap sebesar $76,7 \%$ sedangkan yang tidak puas dengan pelayanan rawat inap sebesar 23,3\%. Standar kepuasan pasien adalah 80\%. Waktu tunggu pelayanan obat jadi adalah tenggang waktu mulai pasien menyerahkan resep sampai dengan menerima obat jadi. Hasil analisis waktu tunggu pelayanan apotek BPJS disajikan dalam Tabel 16 sebagai berikut.

Tabel 16. Waktu Tunggu Pelayanan Apotek BPJS

\begin{tabular}{lccc}
\hline Pelayanan Apotek & Frequensi & Persentase & Standar \\
\hline Tepat Waktu & 46 & 76,7 & \\
Tidak Tepat Waktu & 14 & 23,3 & $\geq 30$ menit \\
Total & 60 & 100,0 & \\
\hline
\end{tabular}

Tabel 19 didapatkan hasil waktu tunggu pelayanan apotek BPJS tepat waktu sebesar 76,7\% sedangkan yang tidak tepat waktu sebesar 23,3\%. Pengiriman laporan setiap tanggal yang telah ditetapkan oleh Dinkes, untuk feed back lebih cepat. Hasil analisis ketepatan waktu pengiriman laporan DOT-TB ke Dinkes disajikan dalam Tabel 20 sebagai berikut.

Tabel 17. Ketepatan Waktu Pengiriman Laporan DOT-TB ke Dinkes

\begin{tabular}{lccc}
\hline Laporan DOT-TB ke dinkes & Frequensi & Persentase & Standar \\
\hline Tepat Waktu & 35 & 58,3 & \\
Tidak Tepat Waktu & 25 & 41,7 & $100 \%$ \\
Total & 60 & 100,0 & \\
\hline
\end{tabular}

Tabel 17 didapatkan hasil ketepatan waktu pengiriman laporan DOT-TB ke Dinkes sebesar 58,3\% sedangkan yang tidak tepat waktu sebesar $41,7 \%$. Standar ketepatan waktu pengiriman laporan adalah 100\%. Berikut adalah ringkasan hasil analisis data pencapaian indikator mutu yang telah dilakukan.

Tabel 18. Ringkasan Hasil Analisis Data Pencapaian Indikator Mutu

\begin{tabular}{clrr}
\hline No. & \multicolumn{1}{c}{ Pengukuran } & Pencapaian (\%) & $\begin{array}{c}\text { Target } \\
(\%)\end{array}$ \\
\hline 1 & Pengkajian Awal Medis & 55 & 100 \\
2 & Waktu Tunggu Pemeriksaan Laboratorium & 70 & 80 \\
3 & Penulisan Resep Obat Sesuai Fornas & 76,7 & 80 \\
4 & Kesalahan Peresepan Obat & 20 & - \\
5 & Kelengkapan Rekam Medis dalam waktu 1x24 & 51,7 & 100 \\
& jam & & \\
6 & Pelaksanaan Time Out di Kamar Operasi & 66,7 & 100 \\
7 & Pengkajian Pra anestesi Sebelum Operasi & 65 & 100 \\
8 & Infeksi Daerah Operasi & 3,3 & 3 \\
\hline
\end{tabular}




\begin{tabular}{clrc}
\hline No. & \multicolumn{1}{c}{ Pengukuran } & Pencapaian (\%) & $\begin{array}{c}\text { Target } \\
(\%)\end{array}$ \\
\hline 9 & Reaksi Tranfusi darah & 5 & 3 \\
10 & Pelaksanaan Etik Klearen Penelitian Klinik & - & - \\
11 & Expertisi Radiologi oleh Radiolog & 65 & 80 \\
12 & Jumlah Pasien Jatuh di Rawat Inap & 3,3 & 0 \\
13 & Kepuasan Pegawai & 71,7 & 80 \\
$14 \quad$ Pelaksanaan Kebersihan Tangan Petugas & 81,7 & 80 \\
& Kesehatan & & \\
15 & Penggunaan MRI Sesuai Dengan Indikasi & 76,7 & 80 \\
16 & Kepuasan Pasien Di Rawat Inap & 76,7 & 80 \\
17 & Waktu Tunggu Pelayanan Apotek & 76,7 & 80 \\
18 & Ketepatan Waktu Pengiriman Laporan Ke Dinkes & 58,3 & 80 \\
\hline
\end{tabular}

Analisa bivariat untuk mencari korelasi atau hubungan antara mutu area klinik/manajerial terhadap sasaran keselamatan pasien. Hasil analisis tersebut disajikan dalam Tabel 19 berikut.

\section{Tabel 19. Hubungan/Korelasi Antara Mutu Klinik/Manajerial dengan} Sasaran Keselamatan Pasien

\begin{tabular}{cllc}
\hline \multirow{2}{*}{ No } & \multicolumn{1}{c}{ Variabel 1 } & \multicolumn{1}{c}{ Variabel 2 } & $\begin{array}{c}\mathrm{p} \leq 0,05 \\
\text { Korelasi }\end{array}$ \\
\cline { 2 - 3 } & Mutu Klinik dan Manajerial & \multicolumn{1}{c}{ Sasaran Keselamatan Pasien } & + \\
\hline 1 & Pengkajian awal medis & Gelang Identitas & + \\
2 & Pengkajian awal medis & Asesmen Risiko Jatuh & + \\
3 & Kelengkapan rekam medik & Gelang Identitas & + \\
4 & Kelengkapan rekam medik & Asesmen Risiko Jatuh & + \\
5 & Penkajian pre anestesi & Gelang Identitas & + \\
6 & Penkajian pre anestesi & Asesmen Risiko Jatuh & + \\
7 & Penkajian pre anestesi & Kepatuhan Prosedur Site Marking & + \\
8 & Kepuasan Pegawai & Asesmen Risiko Jatuh & + \\
\hline
\end{tabular}

\section{PEMBAHASAN}

Pencapaian nilai indikator klinik dan manajerial di RS Dr Suyoto sudah cukup baik, yakni mendekati 80\%, namun perlu ditingkatkan lagi agar mencapai nilai sesuai standar akreditasi. Sebagai perbandingan yang penulis ambil pada RS Nirmalasuri 2017, laporan bulanan mutu Rumah Sakit dengan indikator kepuasan pasien sebagai perbandingan mutu rumah sakit. Dapat dilihat pada http://www.rsnirmalasuri.com/indikator- untuk salah satu indikator yaitu standar kepuasan pasien dan keluarga dilakukan saat pasien sudah dinyatakan boleh pulang.

Selama bulan Januari hingga Oktober 2017 capaian kepuasan pasien dan keluarga menunjukkan diatas standar yaitu 95\% sampai dengan 100\%. Besarnya 
persentase responden yang menyatakan “puas” terhadap pelayanan RS bisa saja terjadi karena konsistensi dan budaya organisasi RS Nirmalasuri, berbeda dengan tingkat kepuasan pasien rawat inap di RS Dr Suyoto dimana didapatkan hasil 76,7\% sudah mendekati standar akreditasi versi KARS 2012 yaitu 80\%.

Untuk hasil signifikansi hubungan/korelasi antar indikator mutu dihubungkan dengan Sasaran Keselamatan Pasien, sebagian variabel indikator Mutu Klinik dan Mutu Manajerial mempunyai hubungan yang signifikan terhadap Sasaran Keselamatan Pasien.

\section{SIMPULAN}

Pencapaian nilai indikator klinik dan manajerial sudah cukup baik, yaitu mendekati 80\%, namun perlu ditingkatkan lagi agar mencapai nilai sesuai standar akreditasi versi KARS 2012. Terdapat Hubungan yang signifikan antara aspek area klinik dan manajerial terhadap Sasaran Keselamatan Pasien. Guna mencapai mutu pelayanan rumah sakit yang baik, terjaminnya keselamatan pasien di instalasi rawat inap dan mencapai akreditasi paripurna dengan cara meningkatkan sosialisasi program dan supervisi. Merencanakan pemilihan prioritas program sesuai kebutuhan, mendukung pelaksanaan program, mempersiapkan sarana prasarana, melatih staff, mengevaluasi, agar mutu klinik, mutu manajerial, dan patient safety dapat tercapai sesuai standar dan dipertahankan hasilnya serta menjadikannya sebagai budaya organisasi.

\section{UCAPAN TERIMA KASIH}

Program Studi Administrasi Rumah Sakit Universitas Respati Indonesia atas bimbingan dan dukungan kepada peneliti.

\section{DAFTAR PUSTAKA}

Assauri, Sofyan.2003. "Costumer Service Yang Baik Landasan Pencapaian Costumer Satisfaction.” Manajemen Usahawan Indonesia.” No. 01, TH. XXXII, Januari.

Ayuningtyas, Dumilah, 2014. Kebijakan Kesehatan Prinsip dan Praktik: Rajawali Pers. Jakarta.

Arifin, Alwi, Darmawansyah, dan A.T.S. Ilma S. 2011. Analisis Mutu Pelayanan 
Kesehatan Ditinjau dari Aspek Input Rumah Sakit di Instalasi Rawat Inap RSU Haji Makassar. Jurnal MKMI, Vol 7 No.1

Azwar, A 2010, Pengantar administrasi kesehatan, edk 3, Binarupa Aksara, Tangerang.

Aprilia, S, 2011, Faktor - faktor yang Mempengaruhi Perawat dalam Penerapan IPSG (Intenational Ptient Safety Goals) pada Akreditasi JCI (Joint Commission International). Skripsi. Jakarta: Fakultas Ilmu Keperawatan Program Pascasarjana Universitas Indonesia Jakarta.

Building a Culture of Patient Safety 2008 - Report of the Commission on Patient Safety and Quality Assurance.

https://health.gov.ie/blog/publications/building-a-culture-of-patient-safetyreport-of-the-commission-on-patient-safety-and-quality-assurance.

Dedi, Uus, Fitriyani 2013, 'Analisis Manajemen Mutu Pelayanan Kesehatan pada Rumah Sakit Islam Karawang',Jurnal Manajemen, vol. 10, no. 3, April. Departemen Kesehatan RI 2006. Tentang Standar Keselamatan Pasien Rumah Sakit. Jakarta. Depkes

Departemen Kesehatan Republik Indonesia. 2008. Legalitas Pendirian Rumah Sakit Swasta, Jakarta, Departemen Kesehatan.

Departemen Kesehatan Republik Indonesia. 2007. Pedoman Penyelenggaraan Rumah Sakit, Jakarta, Departemen Kesehatan;

Emanuel, MD, PhD, etal 2008, What Exactly Is Patient Safety? Advances in Patient Safety: New Directions and Alternative Approaches (Vol. 1: Assessment). https://www.ncbi.nlm.nih.gov/books/NBK43629/

http://fatimatuzzahro-unipdu.blogspot.com/2013/04/pdca-dalam-peningkatanmutu-pelayanan.html

Jeffrey AA, Bryan JW, Stephen MS, Laurence CB, 2007, 'Does quality improvement implementation affect hospital quality of care?', Hospital topics : Research and perspectives on healthcare, vol. 85,no. 2, hh. 3-12.

Jurnal MKMI, maret 2014, Budaya keselamatan pasien di instalasi rawat inap RSUP dr. Wahidin Sudirohusodo kota Makassar

Keputusan Menteri Kesehatan Nomor 428 tahun 2012 tentang penetapan Lembaga Independen Pelaksanaan Akreditasi Rumah Sakit di Indonesia.

Keputusan menteri kesehatan RI No 129/Menkes/SK/II/2008 : Standar rumah sakit di indonesia

Komite Akreditasi Rumah Sakit 2012. Instrumen akreditasi rumah sakit standar Akreditasi Rumah Sakit Versi 2012. Jakarta: Komite Akreditasi Rumah Sakit

Kongres PERSI. 2012. Laporan Peta Nasional Insiden Keselamatan Pasien. Jakarta.

Kotler 2003. Manajemen Pemasaran. Cetakan ke enam. Bogor. Ghalia Indonesia.

Muchlas, M 2008, Perilaku Organisasi, edk 2, Gadjah Mada University Press, Yogyakarta.

Morrow, P. C. 1993. The Theory and Measurement of Work Commitment. Greenwich, CT: JAI.

Notoatmodjo, S., 2014, Ilmu Perilaku Kesehatan, Rineka Cipta, Jakarta. 
Peraturan Menteri Kesehatan Nomor 12 Tahun 2012 Tentang Akreditasi Rumah Sakit

Parasuraman. 1990. Delivering Quality Service. New york: The Free Press

Peraturan menteri kesehatan Nomor 56 Tahun 2014 tentang Klasifikasi dan Perizinan Rumah Sakit

Poerwani, SK dan Sopacua E. 2004. Upaya Pemerintah dalam Penataan

Perumahsakitan di Indonesia Melalui Kegiatan Akreditasi. Makalah dalam Simposium I Badan Litbangkes, Jakarta 20-21 Desember.

Satori, Djam'an dan Komariah, Aan. 2013. Metodologi Penelitian Kualitatif. Bandung: Alfabeta.

Undang-Undang Republik Indonesia nomor 44 tahun 2009 tentang Rumah Sakit Undang-Undang Nomor 36 Tahun 2008 tentang Kesehatan.

Undang-Undang Republik Indonesia Nomor 29 Tahun 2004, Praktek Kedokteran

Sunaringtyas, Rachmawati. 2014. Studi Kualitas Pelayanan Rawat Inap Rumah Sakit dengan Menggunakan Metode Six Sigma. Jurnal MHB, Volume 2.

Setyaningsih, Ira. 2013. Analisis Kualitas Pelayanan Rumah Sakit terhadap Pasien Menggunakan Pendekatan Lean Servperf (Lean Service Performance) (Studi Kasus Rumah Sakit S). Spektrum Industri No. 2, Volume 11.

Tjiptono Fandi, 2004. Strategi Pemasaran. Edisi ke 2.Yogyakarta.

Vincent Charles. 2010, Clinical Safety Research Department of Biosurgery \& Surgical Technology Imperial College London, UK This second edition. Zahrotul. 2008. Kepuasan Pasien Dan Pelayanan Perawat 3. http://roc.uii.ac.id. Diperoleh Tanggal 15 Desember 2011. 